\title{
Peri-procedural use of rivaroxaban in elective percutaneous coronary intervention to treat stable coronary artery disease
}

\section{The X-PLORER trial}

\author{
Pascal Vranckx'; Frank W. G. Leebeek2; Jan G. P. Tijssen³; Jacques Koolen"; Francis Stammen'; Jean-Paul R. Herman ${ }^{6}$; \\ Robbert J. de Winter ${ }^{3}$; Arnout W. J. van t Hof7; Bianca Backx; ${ }^{8}$ Wietze Lindeboom ${ }^{8}$; So-Young Kim ${ }^{9}$; Bodo Kirsch ${ }^{9}$; Martin van Eickels ${ }^{9}$; \\ Frank Misselwitz ${ }^{9}$; Freek W. A. Verheugt ${ }^{6}$ \\ ${ }^{1}$ Department of Cardiac Intensive Care \& Interventional Cardiology Jessaziekenhuis Hasselt, Hartcentrum Hasselt, Belgium; ${ }^{2}$ Department of Hematology, Erasmus University \\ Medical Center, Rotterdam, the Netherlands; ${ }^{3}$ Department of Cardiology, Academisch Medisch Centrum, Amsterdam, the Netherlands; ${ }^{4}$ Department of Cardiology, Catharina- \\ Ziekenhuis, Eindhoven, the Netherlands; ${ }^{5}$ Department of Cardiology, AZ Delta, Roeselare, Belgium; ${ }^{6}$ Department of Cardiology, Onze Lieve Vrouwe Gasthuis, Amsterdam, \\ the Netherlands; ${ }^{7}$ Department of Cardiology, Insala ziekenhuizen Zwolle, the Netherlands; ${ }^{8}$ Cardialysis, Rotterdam, the Netherlands; ${ }^{9}$ Bayer Pharma AG, Leverkusen, Germany
}

\begin{abstract}
Summary
Patients on rivaroxaban requiring percutaneous coronary intervention (PCI) represent a clinical conundrum. We aimed to investigate whether rivaroxaban, with or without an additional bolus of unfractionated heparin (UFH), effectively inhibits coagulation activation during $\mathrm{PCl}$. Stable patients $(n=108)$ undergoing elective $P C I$ and on stable dual antiplatelet therapy were randomised $(2: 2: 2: 1)$ to a short treatment course of rivaroxaban $10 \mathrm{mg}(\mathrm{n}=30)$, rivaroxaban $20 \mathrm{mg}(\mathrm{n}=32)$, rivaroxaban $10 \mathrm{mg}$ plus UFH $(\mathrm{n}=30)$ or standard peri-procedural UFH $(n=16)$. Blood samples for markers of thrombin generation and coagulation activation were drawn prior to and at $0,0.5,2,6-8$ and 48 hours (h) after start of $\mathrm{PCI}$. In patients treated with rivaroxaban (10 or $20 \mathrm{mg}$ ) and patients treated with rivaroxaban plus heparin, the levels of prothrombin fragment $1+2$ at $2 \mathrm{~h}$ post-PCl were $0.16[0.1]$
\end{abstract}

$\mathrm{nmol} / /$ (median) [interquartile range, IQR] and 0.17 [0.2] $\mathrm{nmol} / \mathrm{l}$, respectively. Thrombin-antithrombin complex values at $2 \mathrm{~h}$ post-PCl were 3.90 [6.8] $\mu \mathrm{g} / \mathrm{l}$ and 3.90 [10.1] $\mu \mathrm{g} / \mathrm{l}$, respectively, remaining below the upper reference limit (URL) after $\mathrm{PCl}$ and stenting. This was comparable to the control group of UFH treatment alone. However, median values for thrombin-antithrombin complex passed above the URL with increasing tendency, starting at $2 \mathrm{~h}$ post-PCI in the UFHalone arm but not in rivaroxaban-treated patients. In this exploratory trial, rivaroxaban effectively suppressed coagulation activation after elective $\mathrm{PCl}$ and stenting.

\section{Keywords}

Anticoagulation, coronary artery disease, rivaroxaban, thrombosis

Financial support:

This study was funded by Bayer.

Received: January 21, 2015

Accepted after minor revision: March 4, 2015

Epub ahead of print: April 30, 2015

http://dx.doi.org/10.1160/TH15-01-0061

Thromb Haemost 2015; 114: 258-267

Clinical trial registration: Clinical Trials.gov Identifier: NCT01442792

URL: EudraCT. Unique identifier: No: 2011-001094-58.

\section{Introduction}

Patients on long-term oral anticoagulant treatment for protection against thromboembolic events who are in need of percutaneous coronary intervention (PCI) represent a difficult group to manage.

During PCI, a certain level of anticoagulation is required to perform the procedure safely because balloon inflation and stent placement can induce or further potentiate an existing prothrombotic state around lesion areas and lead to ischaemic complications $(1,2)$. Contemporary practice guidelines for coronary revascularisation are based on clinical trials that have largely excluded patients who receive long-term anticoagulant therapy (3, 4). The choice of concomitant pharmacological therapy is critical, as are the type, number and duration of antithrombotic therapies. The value of a peri-procedural antithrombotic regimen in this high-risk population depends on the balance between prevention of thrombotic and bleeding complications (5).

Rivaroxaban is an oral, direct, dose-dependent factor Xa inhibitor and has established efficacy and safety in the prevention of stroke and systemic embolism in patients with non-valvular atrial fibrillation (AF) (6-9).

Our primary goal was to investigate whether rivaroxaban in combination with stable dual antiplatelet therapy (DAPT; acetylsalicylic acid plus clopidogrel) could adequately suppress coagulation activation after coronary balloon inflation and stenting in stable coronary artery disease. 


\section{Methods}

\section{Study design and oversight}

The X-PLORER trial (evaluating optimal concomitant anticoagulation in rivaroxaban treated patients, an oral direct factor Xainhibitor, during percutaneous coronary revascularisation trial) is a phase IIa, randomised, semi-blind, exploratory study conducted in seven hospitals in Belgium and the Netherlands.

The members of the Steering Committee, including the sponsor (Bayer, Berlin, Germany) representatives were responsible for the design and oversight of the study and for developing the protocol.

The Institutional Review Board at each participating centre approved the protocol. All patients provided written informed consent. The sponsor was responsible for the collection, source verification and maintenance of the data. An independent committee, whose members were unaware of the study group assignments, adjudicated all suspected clinical outcomes. An independent Data Safety Monitoring Board was charged to monitor patient safety and advised the Steering Committee on potential issues that might have occurred during the trial conduct (Appendix 1 in Suppl. Material, available online at www.thrombosis-online.com).

Final analyses were performed by the sponsor and were verified by independent statisticians (WL, JT). The members of the Writing Committee wrote all drafts of the manuscript, verified the data and vouch for the completeness of the data, the accuracy of the analyses and the fidelity of the study to the protocol.

\section{Patients}

Patients aged 18 years or older who were not using long-term oral anticoagulant treatment with warfarin or a direct factor IIa or factor Xa inhibitor and were scheduled to receive PCI to treat symptomatic, obstructive coronary artery disease were included in the study. The condition of patients needed to be stabilised before enrolment with the cardiac-specific troponin at the time of the index PCI below the 99th percentile of the upper reference limit. Patients were excluded for lesion-specific conditions, if they were haemodynamically unstable or if they were at increased risk of bleeding (Appendix 2: main inclusion and exclusion criteria, in Suppl. Material, available online at www.thrombosis-online.com).

\section{Randomisation and study treatments}

After providing written informed consent, all participants were randomly assigned in a 2:2:2:1 fashion to either one of three rivaroxaban (Bayer, Berlin, Germany) investigational arms or to the comparator arm, by means of pre-prepared sealed envelopes $(\triangleright$ Figure 1$)$.

The three pre-specified rivaroxaban treatment arms were: a single dose of rivaroxaban $10 \mathrm{mg}$ alone without additional bolus of heparin; a single dose of rivaroxaban $20 \mathrm{mg}$ alone without additional bolus of heparin; or a single dose of rivaroxaban $10 \mathrm{mg}$ combined with an intravenous bolus of unfractionated heparin (UFH) $50 \mathrm{IU} / \mathrm{kg}$ body weight.

The patients in the control arm received the standard UFH anticoagulation regimen with an intravenous bolus of $70 \mathrm{IU} / \mathrm{kg}$ body weight immediately before the start of PCI, with subsequent boluses (2,500 IU) targeted to achieve an activated clotting time (ACT), measured at 30-minute ( $\mathrm{min}$ ) time intervals after insertion of the catheter sheath, of 250-300 seconds (s). The single doses of rivaroxaban were administered once in a blinded fashion in tablet form containing either $10 \mathrm{mg}$ or $20 \mathrm{mg}$ of the drug 2-4 hours (h) prior to the PCI procedure together with a light meal. Heparin use and dose (adjusting) in the control arm was unblinded. Heparin catheter-flushing in all study arms up to 200 IU/day was mandatory.

All patients were on stable, prophylactic DAPT with a combination of acetylsalicylic acid 75-100 mg and clopidogrel (loading dose of $300 \mathrm{mg}$ and maintenance dose of $75 \mathrm{mg}$ once daily) for at least five days. Glycoprotein (GP)IIb/IIIa inhibitor use was restricted to bail-out situation (as defined below: thrombotic flowlimiting event) in addition to a bolus of heparin (50 IU/kg; maximum 3,500 IU). Coronary stenting with either bare metal or drugeluting stents, according to the choice of the investigator, was the preferred method of PCI.

\section{Laboratory assays}

Blood samples were collected to assess rivaroxaban plasma levels, markers of thrombin generation (prothrombin fragment $1+2$ $[\mathrm{F} 1+2]$ and thrombin-antithrombin [TAT] complex levels) and
Figure 1: Study flow. One patient in the rivaroxaban + UFH arm did not receive any rivaroxaban and was removed from the analysis. $\mathrm{PCl}$, percutaneous coronary intervention; UFH, unfractionated heparin.
C Schattauer 2015

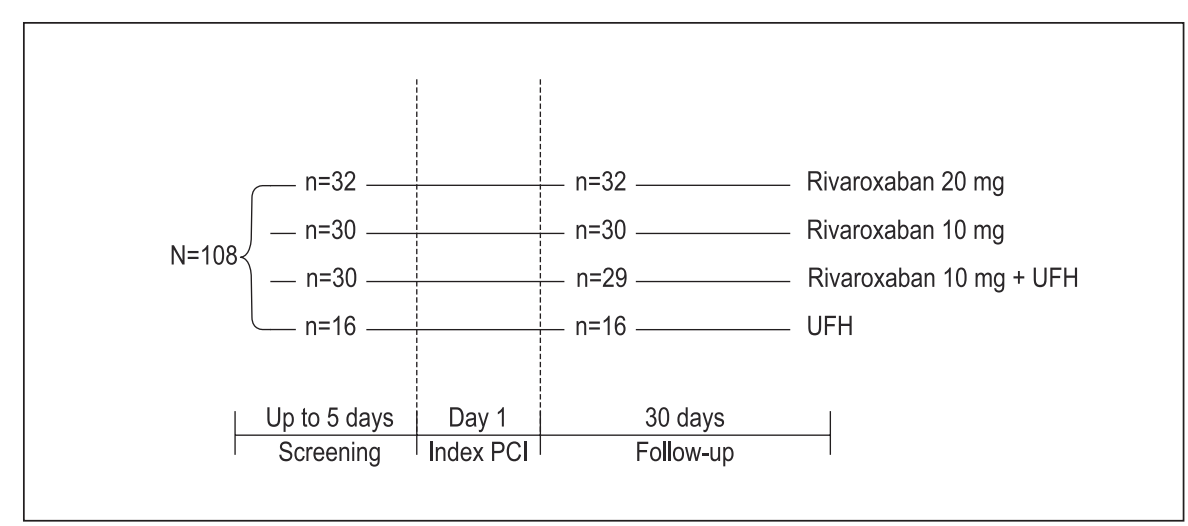


performance of coagulation tests, including anti-factor Xa activity and activated partial thromboplastin time (aPTT), prothrombin time (PT) and endogenous thrombin potential (ETP). Blood samples were obtained at baseline (before study drug administration), before start of the PCI procedure, at $0.5,1,1.5$ and $2 \mathrm{~h}$ during PCI, and at 6-8 and $48 \mathrm{~h}$ (except for rivaroxaban plasma levels) post-PCI. Pharmacokinetic (PK) parameters were calculated by non-compartmental analysis using WinNonlin, version 4.1. Details on the blood sampling and processing procedure, the laboratory coagulation assays and rivaroxaban pharmacokinetics/ pharmacodynamics analysis are detailed in Appendix 3 (in Suppl. Material, available online at www.thrombosis-online.com).

\section{Clinical outcome measures}

In this primarily exploratory study, clinical outcome was assessed by the number of patients who required bail-out antithrombotic therapy in the context of an ischaemic coronary event and/or experienced an angiographic flow-limiting thrombotic event (i.e. abrupt vessel closure, visible thrombus, no reflow) and/or experienced thrombus formation on or within the intervention equipment (i.e. guiding catheter and guide wire) and/or experienced a myocardial infarction (MI) owing to the PCI procedure (i.e. periprocedural MI) (10).

Major ischaemic events were assessed as the composite of allcause death, non-fatal MI, stroke and coronary revascularisation.

The occurrence of major and non-major clinically relevant bleeding and major ischaemic events up to 30 days were also assessed. Major bleeding events, non-major clinically relevant bleeding events and minor bleeding events were classified on the basis of the Bleeding Academic Research Consortium (BARC) and the Thrombolysis in Myocardial Infarction (TIMI) bleeding definitions $(11,12)$. (Suppl. Table 1, available online at www.throm bosis-online.com).

The protocol called for a standard 12-lead electrocardiogram (before the PCI, $6-8 \mathrm{~h}$ post PCI, and $48 \mathrm{~h}$ post-PCI or postdischarge) and the collection of blood samples before the PCI and 6-8 h after the index PCI for measurements of creatine kinase (CK), CK-myocardial band (CK-MB) mass, and cardiac-specific troponin and haemoglobin levels. Patients were clinically followed for adverse events until $30+7$ days after the index PCI procedure.

\section{Statistical analysis}

The primary efficacy analysis was based on the modified intention-to-treat population. The modified intent-to-treat population included all patients who received at least one dose of the study drug. Results from the $10 \mathrm{mg}$ and $20 \mathrm{mg}$ rivaroxaban groups and the $10 \mathrm{mg}$ rivaroxaban plus UFH group were compared with those from the control group. Only descriptive statistics were planned for coagulation plasma measures analysis, including medians and interquartile ranges (IQRs). For all coagulation parameters, median vs time curves were plotted by treatment at the different time points. Clinical outcome measures are reported for descriptive purposes. The study was underpowered for treatment group com- parisons on clinical outcome. No imputation of data was performed. Statistical analyses were performed with the use of SAS software, version 9.2 (SAS Institute Inc., Cary, NC, USA), by dedicated statisticians.

\section{Results \\ Patient demographics}

The X-PLORER trial enrolled 111 patients between October 2011 and March 2013. Three patients failed screening. Of the 108 patients randomised, one patient in the rivaroxaban $10 \mathrm{mg}$ plus UFH group did not receive rivaroxaban and was excluded from the analysis. All other patients $(n=107)$ completed the planned observation period ( $>$ Figure 1 ).

The baseline and procedural characteristics for the population studied are shown in Table 1 (and Suppl. Table 2, available online at www.thrombosis-online.com). The mean age was $64.4 \pm$ 10.5 years. Most patients were male (82/108, $75.9 \%)$. All patients had stable ischaemic coronary artery disease as an indication for PCI. The mean duration of the PCI procedure was $24.9 \pm 19.5$ min; $15 / 107$ patients (14.0\%) had a multi-vessel procedure; one patient had an unplanned stenting of the left main coronary artery.

\section{Coagulation laboratory measurements}

\section{Markers of thrombin generation and activation}

For the markers indicating coagulation activation, including F1+2 and TAT, the baseline values were comparable (Suppl. Table 3, available online at www.thrombosis-online.com).

In all rivaroxaban treatment groups, thrombin generation and propagation during PCI were suppressed, as indicated by low levels of thrombin generation markers: $\mathrm{F} 1+2$ levels at $2.0 \mathrm{~h}$ were 0.16 (0.1) $\mathrm{nmol} / \mathrm{l}$ (median and IQR) in the rivaroxaban $10 \mathrm{mg}$ alone arm, $0.14(0.1) \mathrm{nmol} / \mathrm{l}$ in the $20 \mathrm{mg}$ alone arm, 0.17 (0.2) nmol/l in the rivaroxaban $10 \mathrm{mg}$ plus heparin arm and $0.22(0.2) \mathrm{nmol} / \mathrm{l}$ in the standard UFH-only arm ( Figure 2A). This effect was sustained for up to $48 \mathrm{~h}$ in the rivaroxaban $10 \mathrm{mg}$ and $20 \mathrm{mg}$ alone arms. However, a slight increase in F1+2 to a level of $0.32(0.2)$ $\mathrm{nmol} / \mathrm{l}$ was reported in the standard heparin-only (control) arm at $48 \mathrm{~h}$. A similar pattern was noticed for TAT complex levels (Suppl. Table 3, available online at www.thrombosis-online.com; Figure 2B): TAT complex levels at $2 \mathrm{~h}$ post-PCI were $4.95(11.1) \mu \mathrm{g} / \mathrm{l}$ in the rivaroxaban $10 \mathrm{mg}$ alone arm, $3.50(2.7) \mu \mathrm{g} / \mathrm{l}$ in the rivaroxaban $20 \mathrm{mg}$ alone $\mathrm{arm}, 3.90(10.1) \mu \mathrm{g} / \mathrm{l}$ in the rivaroxaban $10 \mathrm{mg}$ plus UFH arm and 4.60 (11.6) $\mu \mathrm{g} / \mathrm{l}$ in the UFH-only arm. Median values for TAT complex levels passed above the upper limit of normal with increasing tendency, starting at $2 \mathrm{~h}$ post-PCI in the UFH-alone arm but not in any of the three rivaroxaban arms, with the highest result at $48 \mathrm{~h}$ post-PCI $(9.00 \mu \mathrm{g} / \mathrm{l}$; IQR: 20.5).

Likewise, $>$ Figure 3 shows cumulative curves for TAT complex levels (panels A and B) and F1+2 levels (panels C and D) at 2 and $48 \mathrm{~h}$, after the start of PCI plotted for the different study arms. 
Table 1: Baseline characteristics of each treatment group (ITT population). Categorical variables are presented in absolute values and percent $\mathrm{N}$ (\%). $\mathrm{BMI}$, body mass index; BSA, body surface area; CABG, coronary artery bypass grafting; ITT, intention-to-treat; $\mathrm{MI}$, myocardial infarction; PCl, percutaneous coronary intervention; SD, standard deviation.

\begin{tabular}{|c|c|c|c|c|c|}
\hline & $\begin{array}{l}\text { Rivaroxaban } 10 \mathrm{mg} \\
(\mathrm{n}=30)\end{array}$ & $\begin{array}{l}\text { Rivaroxaban } 20 \mathrm{mg} \\
(\mathrm{n}=32)\end{array}$ & $\begin{array}{l}\text { Rivaroxaban } \\
10 \text { or } 20 \mathrm{mg} \\
(\mathrm{n}=62)\end{array}$ & $\begin{array}{l}\text { Rivaroxaban } \\
10 \mathrm{mg} \text { plus heparin } \\
(\mathrm{n}=30)\end{array}$ & $\begin{array}{l}\text { Heparin } \\
(n=16)\end{array}$ \\
\hline Age (years), mean & 61.1 & 64.0 & 62.6 & 66.5 & 67.2 \\
\hline Male sex (\%) & $20(66.7)$ & $26(81.3)$ & $46(74.2)$ & $22(73.3)$ & $14(87.5)$ \\
\hline BMI $\left(\mathrm{kg} / \mathrm{m}^{2}\right)$, mean (SD) & $27.8 \pm 3.7$ & $28.5 \pm 3.2$ & $28.2 \pm 3.5$ & $28.0 \pm 4.6$ & $27.8 \pm 3.6$ \\
\hline $\mathrm{BSA}\left(\mathrm{m}^{2}\right)$, mean $(\mathrm{SD})$ & $2.0(0.2)$ & $2.0(0.2)$ & $2.0(0.2)$ & $2.0(0.2)$ & $2.0(0.2)$ \\
\hline Previous MI (\%) & $3(10.0)$ & $4(12.5)$ & $7(11.3)$ & $6(20.0)$ & $1(6.3)$ \\
\hline Previous PCI (\%) & $3(10.0)$ & $8(25.0)$ & $11(17.17)$ & $3(10.0)$ & $1(6.3)$ \\
\hline Previous CABG (\%) & $1(3.3)$ & $4(12.5)$ & $5(8.1)$ & $1(3.3)$ & $0(0.0)$ \\
\hline Hypertension & $16(53.3)$ & $17(53.1)$ & $33(53.2)$ & $18(60.0)$ & $9(56.3)$ \\
\hline Diabetes mellitus & $2(6.7)$ & $2(6.3)$ & $4(6.5)$ & $4(13.3)$ & $3(18.8)$ \\
\hline Current smoker (\%) & $2(6.7)$ & $5(15.6)$ & $7(11.3)$ & $0(0.0)$ & $1(6.3)$ \\
\hline \multicolumn{6}{|c|}{ Creatinine clearance $(\mathrm{ml} / \mathrm{min})$} \\
\hline$\geq 30-<50 \mathrm{ml}$ & $3(10.0)$ & $2(6.3)$ & $5(8.1)$ & $4(13.3)$ & $1(6.3)$ \\
\hline$\geq 50-<80 \mathrm{ml}$ & $22(73.3)$ & $27(84.4)$ & $49(79.0)$ & $20(66.7)$ & $10(62.5)$ \\
\hline$\geq 80 \mathrm{ml}$ & $5(16.7)$ & $3(9.4)$ & $8(12.9)$ & $6(20.0)$ & $5(31.3)$ \\
\hline
\end{tabular}

Peak levels of F1+2 and TAT complex for the three rivaroxaban arms remained consistently in range with those measured for UFH.

\section{Markers of anticoagulation}

\section{Coagulation tests}

The results on the coagulation tests studied are visualised in $\mathbf{\nabla i g}$ ure 2 and listed in Suppl. Table 3 (available online at www.throm bosis-online.com).

The anti-factor Xa activity increased from 0.10 (0) U/ml (median and $\mathrm{IQR})$ to a maximum of $1.29(1.0) \mathrm{U} / \mathrm{ml}$ in the rivaroxaban $20 \mathrm{mg}$ group at $30 \mathrm{~min}, 1.83(0.4) \mathrm{U} / \mathrm{ml}$ the rivaroxaban $10 \mathrm{mg}$ plus UFH group at $30 \mathrm{~min}$ and $1.38(0.8) \mathrm{U} / \mathrm{ml}$ in the UFH-alone group at $30 \mathrm{~min}$. The rivaroxaban $10 \mathrm{mg}$ plus UFH group had the highest anti-factor Xa levels compared with pre-PCI values ( $>$ Figure 2C).

PT was prolonged by rivaroxaban $20 \mathrm{mg}$ only to $14.25(2.5) \mathrm{s}$ immediately before the start of the PCI procedure vs $11.00(0.9) \mathrm{s}$ before study drug administration; however, PT remained below $15 \mathrm{~s}(>$ Figure 2D). Thrombin time was not influenced by factor Xa inhibition.

The aPTT was more prolonged with UFH within the first $2 \mathrm{~h}$ after PCI compared with rivaroxaban. The aPTT increased from $32.0(5.0) \mathrm{s}$ to a maximum of $48.50(11.0) \mathrm{s}$ at the time of the PCI in the rivaroxaban group. The aPTT exceeded $180 \mathrm{~s}$ in all heparin groups ( $\triangleright$ Figure 2E). A similar pattern was observed for ACT.
Treatment with rivaroxaban decreased the ETP by $>50.0 \%$ and in a dose-dependent manner, but not to the same extent as with heparin $(\triangleright$ Figure $2 \mathrm{~F})$.

\section{Markers of anticoagulation vs rivaroxaban plasma concentrations}

\section{Pharmacokinetic measurements}

The area under the curve and maximum concentrations for the different rivaroxaban regimens are listed in Suppl. Table 4 (available online at www.thrombosis-online.com). The PK parameters of rivaroxaban, including area under the concentration-time curve and maximum plasma concentration, showed a dose-related linear increase from the $10 \mathrm{mg}$ dose to the $20 \mathrm{mg}$ dose. The PK parameters of the $10 \mathrm{mg}$ dose were comparable across both treatment groups (with or without UFH).

Following one dose of the study drug, median rivaroxaban plasma concentrations at the time of PCI were 155.89 (IQR: 86.9) $\mu \mathrm{g} / \mathrm{l}$ for the $10 \mathrm{mg}$ dose group, 250.99 (IQR: 206.8) $\mu \mathrm{g} / \mathrm{l}$ for the $20 \mathrm{mg}$ dose group and 206.05 (IQR: 64.7) $\mu \mathrm{g} / \mathrm{l}$ for the rivaroxaban $10 \mathrm{mg}$ plus heparin group. Plasma levels progressively declined over time with concentrations at $6-8 \mathrm{~h}$ of 43.65 (IQR: 28.7$) \mu \mathrm{g} / \mathrm{l}$ for the $10 \mathrm{mg}$ dose group, 104.76 (IQR: 50.4 ) $\mu \mathrm{g} / \mathrm{l}$ for the $20 \mathrm{mg}$ dose group and 55.70 (IQR: 38.1$) \mu \mathrm{g} / \mathrm{l}$ for the rivaroxaban $10 \mathrm{mg}$ plus heparin group.

The relationship between rivaroxaban plasma concentrations and a selection of the coagulation parameters (anti-factor Xa, 
aPTT, PT and ETP) are presented in $>$ Figure 4A-D. This includes all blood samples taken during the study.

Anti-factor Xa activity rose sharply with increasing plasma concentrations in the clinically relevant drug concentration range of rivaroxaban $[0.09921+0.00534$ (PK concentration); R-square = 0.73 , p-value $<0.0001$ ] (Suppl. Table 5, available online at www. thrombosis-online.com).

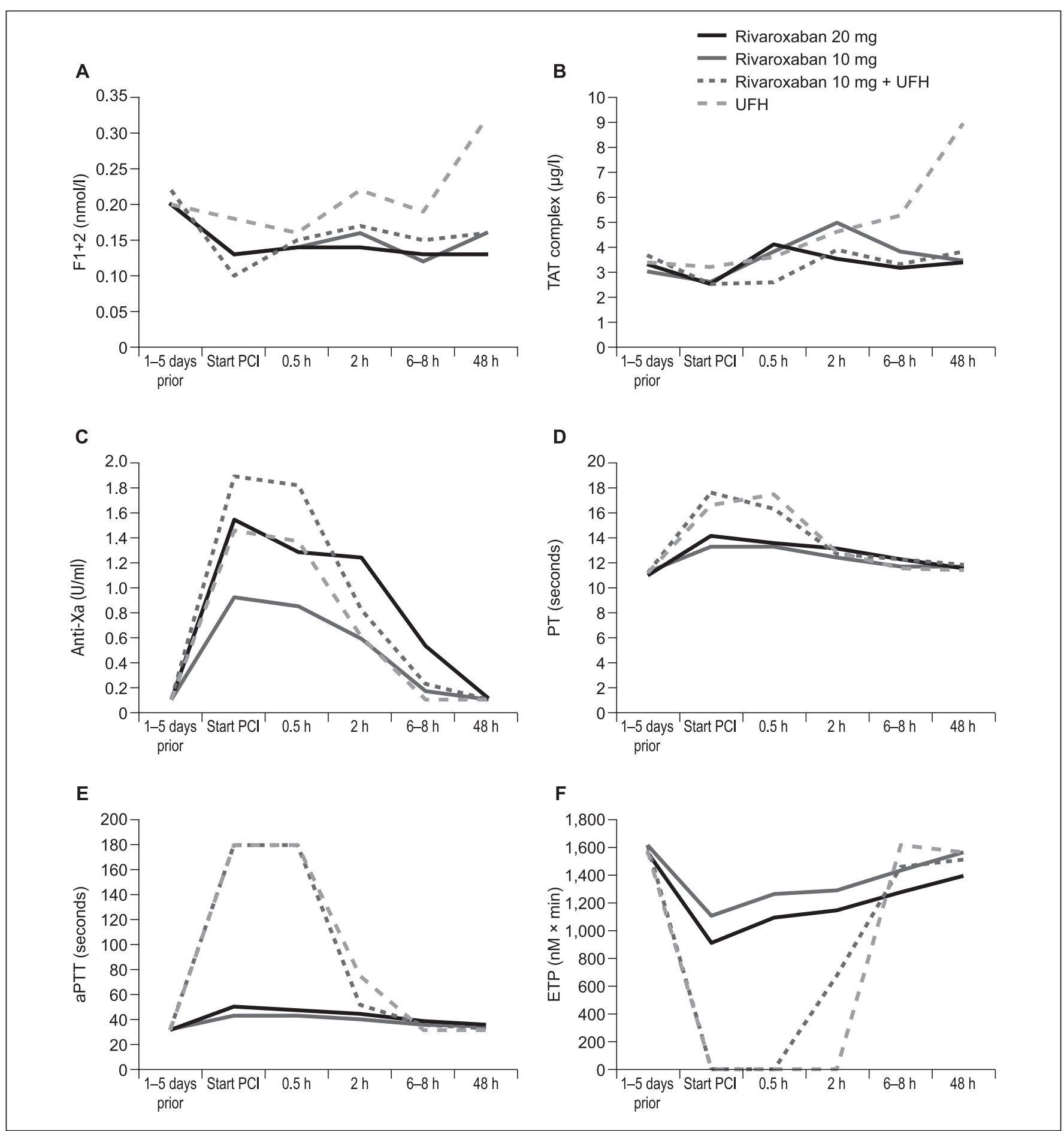

Figure 2: Median vs time curves plotted by individual treatment. Median prothrombin fragment $1+2$ levels $(A)$; thrombin-antithrombin complex levels (B); anti-factor Xa activity (C); prothrombin time (D); activated partial thromboplastin time (E); endogenous thrombin potential $(\mathrm{F})$ per treat- ment. Anti-Xa, anti-factor Xa; aPTT, activated partial thromboplastin time; ETP, endogenous thrombin potential; $\mathrm{F} 1+2$, prothrombin fragment $1+2 ; \mathrm{PCl}$, percutaneous coronary intervention; PT, prothrombin time; TAT, thrombinantithrombin; UFH, unfractionated heparin. 


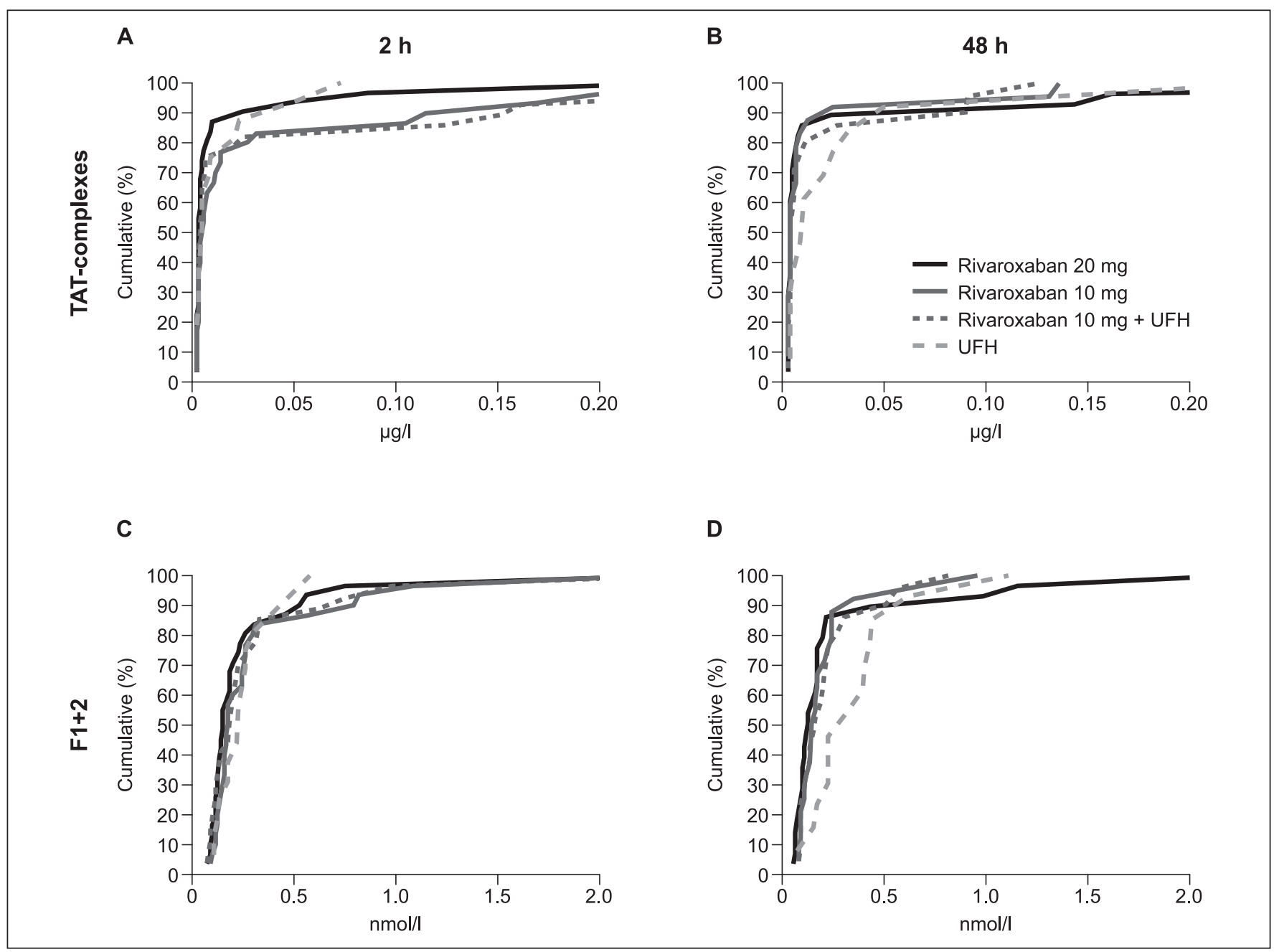

Figure 3: Cumulative curves for thrombin-antithrombin III complex (A, B) and prothrombin fragment 1+2 (C, D) at 2 (A, C) and $48(B, D) h$ after the start of the percutaneous coronary intervention. Start $\mathrm{PCl}=$ baseline. $\mathrm{F} 1+2$, prothrombin fragment $1+2 ; \mathrm{PCl}$, percutaneous coronary intervention; TAT, thrombin-antithrombin; UFH, unfractionated heparin.

\section{Clinical outcomes}

There were no patients in the three rivaroxaban arms that required bail-out antithrombotic medication and/or had clinical signs of catheter-related thrombosis. ( $\$$ Table 2, clinical outcomes). Twelve of the total 107 patients $(11.2 \%)$ experienced a periprocedural MI. Five of the 12 patients were symptomatic: $2 / 5$ patients in the UFH group, $2 / 4$ in the rivaroxaban $10 \mathrm{mg}$ plus UFH group and $1 / 3$ in the rivaroxaban $20 \mathrm{mg}$ group. Two patients, both in the rivaroxaban plus heparin arm, experienced a flow-limiting complication (one target vessel dissection, one side branch occlusion), none were thrombotic. There were no deaths or Academic Research Consortium-defined probable or definite stent thrombosis.

There were no TIMI significant (major and minor combined) or BARC class 3 or 5 bleeding events up to 30 days following the index procedure ( $\$$ Table 2 , clinical outcomes).

\section{Discussion}

The oral, direct, factor Xa inhibitor rivaroxaban is registered for use in a number of clinical settings, including: primary prevention of venous thromboembolism in patients undergoing elective total hip or knee replacement surgery; treatment and secondary prevention of deep-vein thrombosis and pulmonary embolism; stroke prophylaxis in patients with non-valvular AF; and secondary prevention of acute coronary syndrome (ACS) in Europe. The estimated prevalence of $\mathrm{AF}$ is $1-2 \%$; up to approximately $20 \%$ of these patients will require PCI over time (13). Indeed, 1-2 million patients with $\mathrm{AF}$ in Europe who are on oral anticoagulant may undergo PCI, usually including stenting (13). However, the paucity of data on patients undergoing PCI with rivaroxaban today is notable. X-PLORER is a small, dedicated, pharmacology-intervention trial - the first to randomise a novel, oral, direct factor Xa inhibitor against standard UFH on the background of stable DAPT in patients undergoing an elective PCI. 
Our study showed that rivaroxaban at a dose of 10 or $20 \mathrm{mg}$ or $10 \mathrm{mg}$ in addition to UFH effectively suppressed thrombin generation during and shortly after PCI.

Although this was a study with a limited number of patients, rivaroxaban administered once before the procedure seems to provide sufficient anticoagulation to prevent adverse ischaemic coronary events after coronary stenting. Neither an angiographic flow-limiting thrombotic complication nor any thrombus formation on the PCI equipment occurred in our study patients. There was no excess in peri-procedural (Type IVa) MI. Preprocedural anticoagulation with rivaroxaban was not associated with any safety signal towards an increase in any actionable bleeding events. The PK parameter estimates for a single administration of rivaroxaban in PCI patients $2-4 \mathrm{~h}$ before the intervention increased dose linearly from $10 \mathrm{mg}$ dose to $20 \mathrm{mg}$ dose and were comparable to those published for other populations and indications (14).

Rivaroxaban is an effective and well-characterised anticoagulant (14-20). The pharmacokinetic profile of rivaroxaban is consistent in healthy subjects and across a broad range of different patient populations studied $(16,17,20)$. Rivaroxaban is absorbed rapidly, with maximum concentrations $\left(\mathrm{C}_{\max }\right)$ appearing $2-4 \mathrm{~h}$ after single tablet intake, and maximal factor Xa inhibition seen after 1-4 h $(14,18)$. At total daily oral doses of rivaroxaban of $5-60 \mathrm{mg}, \mathrm{C}_{\max }$ ranges (mean values) from $40 \mu \mathrm{g} / \mathrm{l}$ to $400 \mu \mathrm{g} / \mathrm{l}$, and minimum plasma concentration $\left(\mathrm{C}_{\text {trough }}\right)$ (mean values) from 8 $\mu \mathrm{g} / \mathrm{l}$ to $160 \mu \mathrm{g} / \mathrm{l}(16,17,19,20)$.

The X-PLORER trial was aimed at patients receiving $20 \mathrm{mg}$ rivaroxaban once daily for chronic anticoagulation therapy. None of the patients in our study population had an indication for

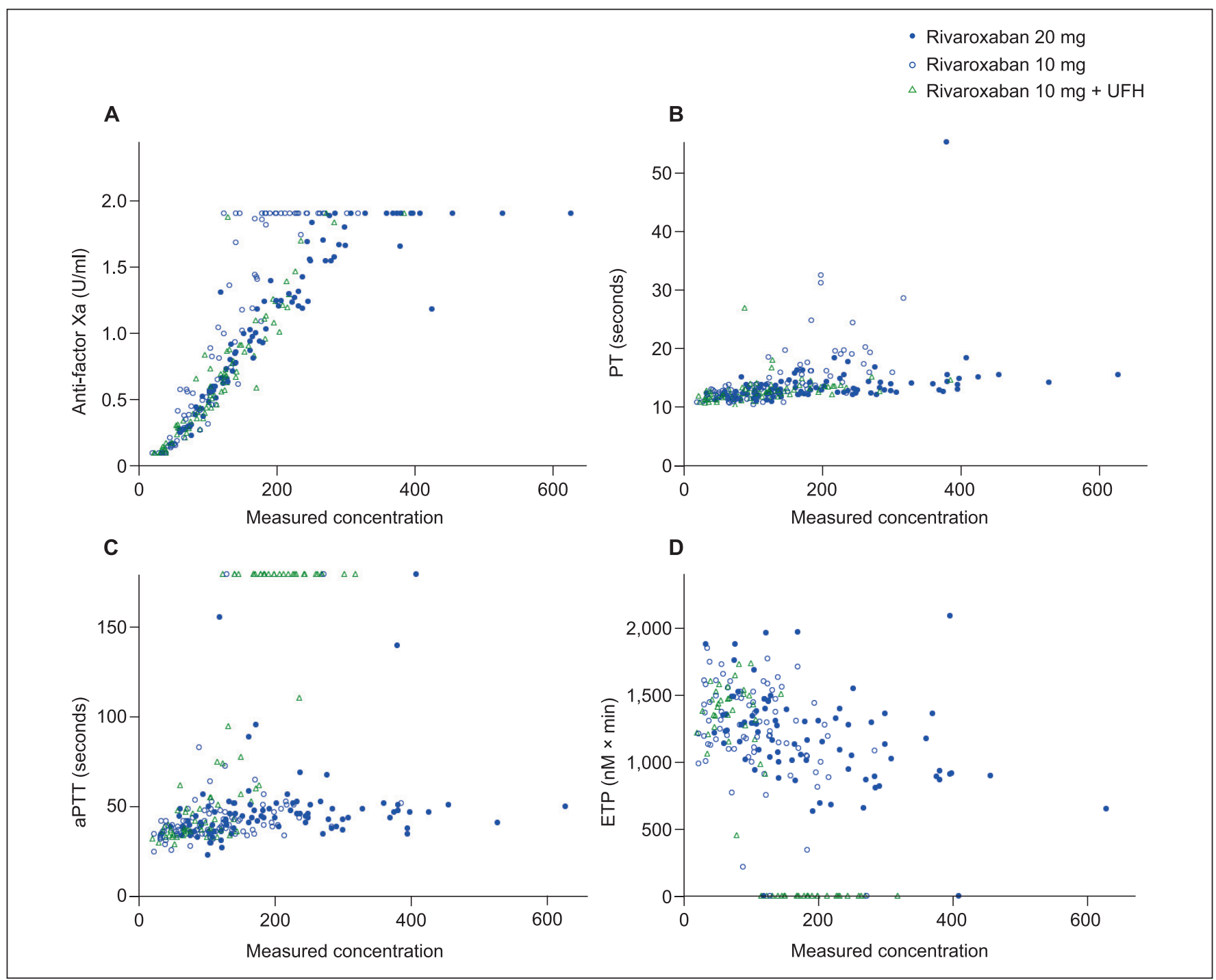

Figure 4: Relationship between rivaroxaban plasma level and the result of coagulation tests. Anti-factor Xa activity (A); prothrombin time (B); activated partial thromboplastin time (C); endogenous thrombin potential (D). aPTT, activated partial thromboplastin time; ETP, endogenous thrombin potential; PT, prothrombin time; UFH, unfractionated heparin. 
Table 2: Clinical outcomes (mITT population). BARC, Bleeding Academic Research Consortium; mITT, modified intention-to-treat; TIMI, Thrombolysis In Myocardial Infarction.

\begin{tabular}{|c|c|c|c|c|c|}
\hline & $\begin{array}{l}\text { Rivaroxaban } \\
10 \mathrm{mg} \\
(\mathrm{n}=30)\end{array}$ & $\begin{array}{l}\text { Rivaroxaban } \\
20 \mathrm{mg} \\
(\mathrm{n}=32)\end{array}$ & $\begin{array}{l}\text { Rivaroxaban } \\
10 \text { or } 20 \mathrm{mg} \\
(\mathrm{n}=62)\end{array}$ & $\begin{array}{l}\text { Rivaroxaban } \\
10 \mathrm{mg} \text { plus } \\
\text { heparin } \\
(\mathrm{n}=29)\end{array}$ & $\begin{array}{l}\text { Heparin } \\
(n=16)\end{array}$ \\
\hline $\begin{array}{l}\text { Bail-out } \\
\text { anticoagulation } \\
\text { therapy and/or } \\
\text { flow-limiting } \\
\text { thrombotic event }\end{array}$ & $0(0)$ & $0(0)$ & $0(0)$ & $0(0)$ & $1(6.3)$ \\
\hline \multicolumn{6}{|c|}{ Myocardial infarction } \\
\hline Peri-procedural & $0(0)$ & $3(9.4)$ & $3(4.8)$ & $4(13.8)$ & $5(31.3)$ \\
\hline $\begin{array}{l}\text { Spontaneous, up } \\
\text { to } 30 \text { days }\end{array}$ & $0(0)$ & $0(0)$ & $0(0)$ & $0(0)$ & $0(0)$ \\
\hline \multicolumn{6}{|l|}{ Bleeding } \\
\hline \multicolumn{6}{|l|}{$\begin{array}{l}\text { TIMI } \\
\text { classification }\end{array}$} \\
\hline $\begin{array}{l}\text { Significant } \\
\text { (major or } \\
\text { minor) }\end{array}$ & $0(0)$ & $0(0)$ & $0(0)$ & $0(0)$ & $0(0)$ \\
\hline $\begin{array}{l}\text { Requiring } \\
\text { medical } \\
\text { attention }\end{array}$ & $4(13.3)$ & 1 (3.1) & $5(8.1)$ & $5(17.2)$ & $4(25.0)$ \\
\hline \multicolumn{6}{|l|}{ BARC classification } \\
\hline 2 & $3(10.0)$ & $1(3.1)$ & $4(6.5)$ & $4(13.8)$ & $3(18.8)$ \\
\hline 3 or 5 & $0(0)$ & $0(0)$ & $0(0)$ & $0(0)$ & $0(0)$ \\
\hline
\end{tabular}

chronic anticoagulant therapy and, therefore, only received a single dose of rivaroxaban. However, owing to the pharmacokinetics of rivaroxaban (e.g. fast onset of action and no accumulation), a single dose was considered acceptable and predictive for multiple-dose administration. The doses used in X-PLORER were expected to mimic the peak plasma levels obtained between 2 and $12 \mathrm{~h}$ after the last intake of rivaroxaban $20 \mathrm{mg}$ and allows an assessment of a PCI performed in this time period (18). However, in the absence of a more robust exposure response analysis, the observed efficacy should not be extrapolated to trough levels.

There is a close relationship between rivaroxaban plasma concentrations and anti-factor Xa activity, thus providing evidence that anti-factor Xa activity may be a suitable tool to indirectly estimate rivaroxaban plasma concentrations if necessary. The correlation between the plasma concentration of rivaroxaban and prolongation of PT depends on the sensitivity of the reagent; a close correlation ( $r$-square $=0.98)$ is observed with Neoplastin (15). The results with other PT reagents may differ from those obtained with the Neoplastin assay. Because Pathromtin SL was used in this study, the dose-dependent increase in PT within the first few hours may have been somewhat flatter than anticipated based on published data (21).

In this by-design mechanistic study, the main focus was the peri-procedural results of coagulation tests and levels of markers of coagulation. Levels of F1+2 and TAT complexes, which are both markers of thrombin generation, were suppressed in all rivaroxaban groups after PCI and showed similar results to the control arm that received UFH alone. This may be explained by the fact that, by inhibiting factor $\mathrm{Xa}$, both rivaroxaban and heparin act at the confluence of both the intrinsic and extrinsic pathways of coagulation and, at the same time, exert control at the critical thrombin generation amplification point. Of potential interest was a signal pointing at a reactivation of thrombin generation beyond 6 hours after the index PCI in the heparin-alone arm, indicated by an increase in thrombin-generation markers, which was not observed in the rivaroxaban arms. This observation is not new and may result from an imbalance between ongoing prothrombotic forces and decreasing antithrombotic activity after the withdrawal of heparin (22).

The results of X-PLORER contrast with those of the Randomized, Open-label, Dose-Ranging study of Dabigatran Etexilate, a Novel, Oral, Direct Thrombin-inhibitor in clinical development, in Elective Percutaneous Coronary Intervention (D-fine) study (23). Although the studies have some differences in study design and measurements of coagulation activation, the setting and patients included were comparable. Dabigatran (110 mg or $150 \mathrm{mg}$ twice daily) did not provide sufficient anticoagulation to suppress coagulation activation during and after PCI and stenting, indicated by a consistent increase in the levels of F1+2 and TAT complex measured, compared with UFH alone. 
This study has multiple limitations. First, the limitation of an open-label study design should be acknowledged. Only the two single rivaroxaban doses were blinded. However, the laboratory technicians were not aware of the treatment the individual patients received. Furthermore, the study was limited to elective PCI in stable patients. Patients with more complex lesion morphology and ongoing myocardial ischaemia may be at higher risk of periprocedural thrombotic complications (e.g. complex lesion morphology; ST-segment elevation MI) and in need of even more intense peri-procedural anticoagulation.

As indicated earlier, X-PLORER was only exploratory by design and was not powered to detect any difference in clinical or angiographic thrombotic complications among its three arms. Overall, the trial was too small to draw any conclusion regarding differences in clinical outcome. However, the absence of serious ischaemic events with an excess of major or non-major clinically relevant bleeding events is reassuring. Our data may offer the background for an outcome study testing rivaroxaban following PCI.

Patients who present with ACS remain at high risk of recurrent cardiovascular events. This is despite the use of currently recommended 12-month antiplatelet therapy (i.e. DAPT), revascularisation procedures as appropriate, and other evidence-based secondary prevention measures (24-26) . The risk may be related in part to excess thrombin generation that persists beyond the acute presentation (27). The addition of very low dose anticoagulation with rivaroxaban to DAPT represents a new treatment strategy for this important population (28). Given the delicate balance between bleeding risks and the ischaemic benefits of periprocedural antithrombotic treatment, we need a better understanding of the role of rivaroxaban in higher-risk patients with ACS undergoing revascularisation. Additional well-designed, adequately powered, randomised clinical trials testing new combinations of drugs, and eliminating older ones, and that assess both bleeding and ischaemic outcomes will be necessary. In the meantime, X-PLORER provides an initial indication that rivaroxaban does not need to be stopped at the time of a PCI.

\section{What is known about this topic?}

- Patients taking rivaroxaban for protection against thromboembolic events who are in need of percutaneous coronary intervention (PCI) represent a difficult group to manage.

- Recommendations for antithrombotic treatment in patients undergoing $\mathrm{PCl}$ who require oral anticoagulation are largely based on expert opinion.

\section{What does this paper add?}

- The results of this mechanistic trial may be conceived as a first step in exploring rivaroxaban in a dual-pathway strategy, targeting both thrombin and platelets, for ischaemic coronary event reduction in patients undergoing $\mathrm{PCl}$.

\section{Conclusions}

In conclusion, in this exploratory trial, we have shown that, in patients on stable DAPT, rivaroxaban provided sufficient anticoagulation to suppress thrombin generation during elective PCI and stenting. These results warrant confirmation in a larger PCI trial that includes high-risk patients with ACS and is adequately powered to assess both bleeding and ischaemic outcomes.

\section{Acknowledgements}

The authors would like to acknowledge Abigail Macleod, who provided language editing support with funding from Bayer HealthCare Pharmaceuticals and Janssen Scientific Affairs, LLC. We thank the study staff at the participating centres for their efforts in collecting the data and the patients who volunteered to participate in the study.

\section{Conflicts of interest}

Pascal Vranckx has received research grants from Bayer HealthCare, Boehringer Ingelheim and Daiichi Sankyo; honoraria for advisory board and lectures from BMS-Pfizer. Freek W. A. Verheugt has received honoraria for consulting and speaking from Bayer HealthCare, Boehringer Ingelheim, BMS/Pfizer and Daiichi Sankyo. So-Young Kim, Bodo Kirsch, Martin van Eickels and Frank Misselwitz report being employees of Bayer HealthCare. No other potential conflict of interest relevant to this article was reported.

\section{References}

1. Leon MB, Baim DS, Popma JJ, et al. A clinical trial comparing three antithrombotic-drug regimens after coronary-artery stenting. Stent Anticoagulation Restenosis Study Investigators. N Engl J Med 1998; 339: 1665-1671.

2. Mann KG. Thrombin formation. Chest 2003; 124 (Suppl 3): 4S-10S.

3. Silber S, Albertsson P, Aviles FF, et al. Guidelines for percutaneous coronary interventions. The Task Force for Percutaneous Coronary Interventions of the European Society of Cardiology. Eur Heart J 2005; 26: 804-847.

4. King SB, III, Smith SC, Jr., Hirshfeld JW, Jr., et al. 2007 Focused update of the ACC/AHA/SCAI 2005 guideline update for percutaneous coronary intervention: a report of the American College of Cardiology/American Heart Association Task Force on Practice Guidelines: 2007 writing group to review new evidence and update the ACC/AHA/SCAI 2005 guideline update for percutaneous coronary intervention, writing on behalf of the 2005 writing committee. Circulation 2008; 117: 261-295.

5. Ndrepepa G, Berger PB, Mehilli J, et al. Periprocedural bleeding and 1-year outcome after percutaneous coronary interventions: appropriateness of including bleeding as a component of a quadruple end point. J Am Coll Cardiol 2008; 51: 690-697.

6. Perzborn E, Strassburger J, Wilmen A, et al. In vitro and in vivo studies of the novel antithrombotic agent BAY 59-7939 $\square-$ an oral, direct Factor Xa inhibitor. J Thromb Haemost 2005; 3: 514-521.

7. Kubitza D, Becka M, Wensing G, et al. Safety, pharmacodynamics, and pharmacokinetics of BAY 59-7939--an oral, direct Factor Xa inhibitor--after multiple dosing in healthy male subjects. Eur J Clin Pharmacol 2005; 61: 873-880.

8. Kubitza D, Becka M, Roth A, et al. Dose-escalation study of the pharmacokinetics and pharmacodynamics of rivaroxaban in healthy elderly subjects. Curr Med Res Opin 2008; 24: 2757-2765.

9. Patel MR, Mahaffey KW, Garg J, et al. Rivaroxaban versus warfarin in nonvalvular atrial fibrillation. N Engl J Med 2011; 365: 883-891. 
10. Thygesen K, Alpert JS, White HD, et al. Universal definition of myocardial infarction. Circulation 2007; 116: 2634-2653.

11. Mehran R, Rao SV, Bhatt DL, et al. Standardized bleeding definitions for cardiovascular clinical trials: a consensus report from the Bleeding Academic Research Consortium. Circulation 2011; 123: 2736-2747.

12. Rao AK, Pratt C, Berke A, et al. Thrombolysis in Myocardial Infarction (TIMI) trial-phase I: hemorrhagic manifestations and changes in plasma fibrinogen and the fibrinolytic system in patients treated with recombinant tissue plasminogen activator and streptokinase. J Am Coll Cardiol 1988; 11: 1-11.

13. Lip GYH, Windecker S, Huber K, et al. Management of antithrombotic therapy in atrial fibrillation patients presenting with acute coronary syndrome and/or undergoing percutaneous coronary or valve interventions: a joint consensus document of the European Society of Cardiology Working Group on Thrombosis, European Heart Rhythm Association (EHRA), European Association of Percutaneous Cardiovascular Interventions (EAPCI) and European Association of Acute Cardiac Care (ACCA) endorsed by the Heart Rhythm Society (HRS) and Asia-Pacific Heart Rhythm Society (APHRS). Eur Heart J 2014; 35: 3155-3179.

14. Mueck W, Stampfuss J, Kubitza D, et al. Clinical pharmacokinetic and pharmacodynamic profile of rivaroxaban. Clin Pharmacokinet 2014; 53: 1-16.

15. Bayer Pharma AG. Xarelto (rivaroxaban) Summary of Product Characteristics. 2014. Available at: http://www.ema.europa.eu/docs/en_GB/document_library/ EPAR__Product_Information/human/000944/WC500057108.pdf. Accessed January 6, 2015.

16. Mueck W, Eriksson BI, Bauer KA, et al. Population pharmacokinetics and pharmacodynamics of rivaroxaban - an oral, direct Factor Xa inhibitor - in patients undergoing major orthopaedic surgery. Clin Pharmacokinet 2008; 47: 203-216.

17. Mueck W, Lensing AWA, Agnelli G, et al. Rivaroxaban: population pharmacokinetic analyses in patients treated for acute deep-vein thrombosis and exposure simulations in patients with atrial fibrillation treated for stroke prevention. Clin Pharmacokinet 2011; 50: 675-686.

18. Mueck W, Schwers S, Stampfuss J. Rivaroxaban and other novel oral anticoagulants: pharmacokinetics in healthy subjects, specific patient populations and relevance of coagulation monitoring. Thromb J 2013; 11: 10.

19. Samama MM, Contant G, Spiro TE, et al. Laboratory assessment of rivaroxaban: a review. Thromb J 2013; 11: 11.

20. Xu XS, Moore K, Burton P, et al. Population pharmacokinetics and pharmacodynamics of rivaroxaban in patients with acute coronary syndromes. Br J Clin Pharmacol 2012; 74: 86-97.

21. Samama MM, Martinoli JL, Le Flem L, et al. Assessment of laboratory assays to measure rivaroxaban - an oral, direct Factor Xa inhibitor. Thromb Haemost 2010; 103: 815-825.

22. Theroux P, Waters D, Lam J, et al. Reactivation of unstable angina after the discontinuation of heparin. N Engl J Med 1992; 327: 141-145.

23. Vranckx P, Verheugt FW, de Maat MP, et al. A randomised study of dabigatran in elective percutaneous coronary intervention in stable coronary artery disease patients. EuroIntervention 2013; 8: 1052-1060.

24. Mauri L, Kereiakes DJ, Yeh RW, et al. Twelve or 30 months of dual antiplatelet therapy after drug-eluting stents. N Engl J Med 2014; 371: 2155-2166.

25. Stone GW, Maehara A, Lansky AJ, et al. A prospective natural-history study of coronary atherosclerosis. N Engl J Med 2011; 364: 226-235.

26. Wiviott SD, Braunwald E, McCabe $\mathrm{CH}$, et al. Prasugrel versus clopidogrel in patients with acute coronary syndromes. N Engl J Med 2007; 357: 2001-2015.

27. Merlini PA, Bauer KA, Oltrona L, et al. Persistent activation of coagulation mechanism in unstable angina and myocardial infarction. Circulation 1994; 90: 61-68.

28. Mega JL, Braunwald E, Wiviott SD, et al. Rivaroxaban in patients with a recent acute coronary syndrome. N Engl J Med 2012; 366: 9-19.

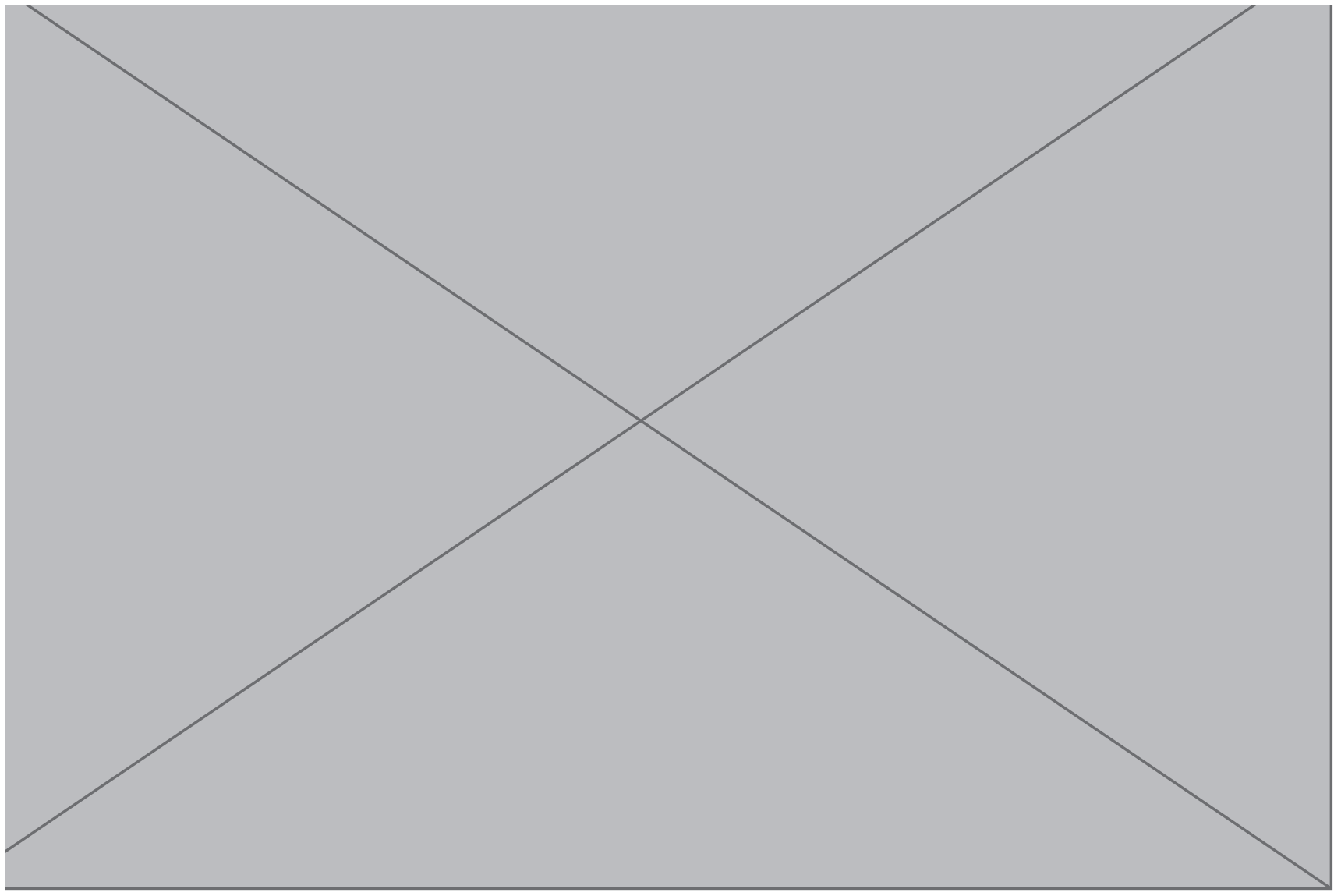

